DEPARTMENT OF THE INTERIOR

U.S. GEOLOGICAL SURVEY

\title{
COMPILATION OF SELECTED GEOPHYSICAL REFERENCES FOR THE SNAKE RIVER PLAIN, IDAHO AND EASTERN OREGON
}

By R. L. Whitehead

A contribution of the REGIONAL AQUIFER-SYSTEM ANALYSIS PROGRAM

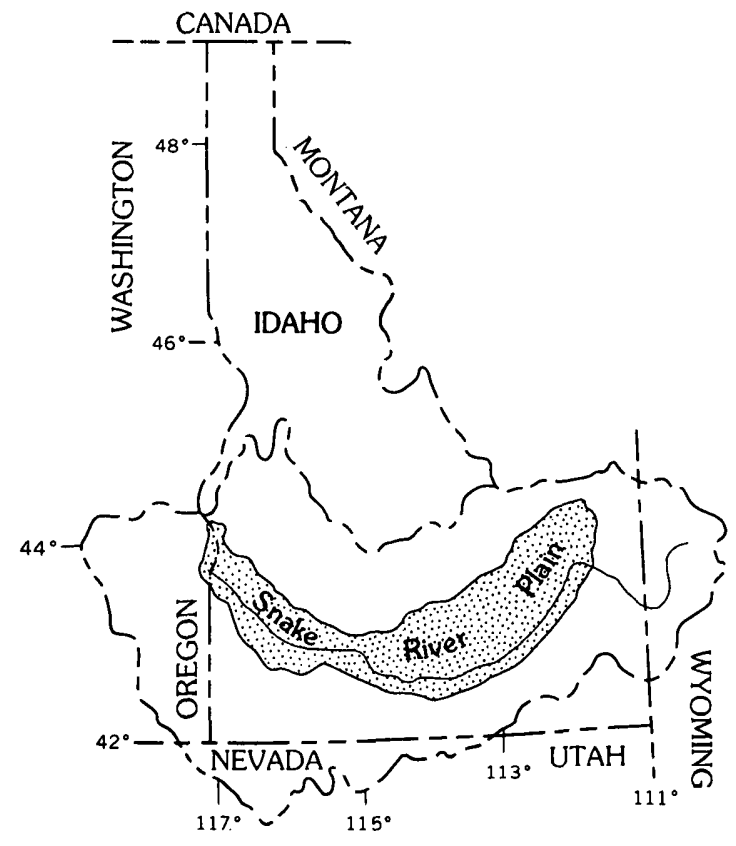

GEOPHYSICAL INVESTIGATIONS MAP

Published by the U.S. Geological Survey, 1986

W 